\title{
Apoptosis of U937 human leukemic cells by sodium butyrate is associated with inhibition of telomerase activity
}

\author{
YUNG HYUN CHOI

\begin{abstract}
Department of Biochemistry, Dongeui University College of Oriental Medicine and Department of Biomaterial Control, Dongeui University Graduate School, Busan 614-052, South Korea
\end{abstract}

Received April 3, 2006; Accepted May 30, 2006

\begin{abstract}
Sodium butyrate as a histone deacetylase inhibitor is known to exhibit anti-cancer effects via the differentiation and apoptosis of various carcinoma cells. However, the mechanism by which sodium butyrate induces apoptosis and the involvement of telomerase activity during apoptosis is not completely understood. To investigate the underlying pathways, sodium butyrate's potential to induce apoptosis in human leukemic U937 cells and its effects on telomerase activity were investigated. Exposure of U937 cells to sodium butyrate resulted in growth inhibition and induction of apoptosis in a dose-dependent manner as measured by hemocytometer counts, fluorescence microscopy, agarose gel electrophoresis and flow cytometry analysis. The increase in apoptosis was associated with the up-regulation in pro-apoptotic Bax expression, and down-regulation of anti-apoptotic Bcl-2 and $\mathrm{Bcl}-\mathrm{X}_{\mathrm{L}}$. Sodium butyrate treatment also inhibited the levels of cIAP family members and induced the activation of caspase-3. Furthermore, sodium butyrate markedly inhibited the activity of telomerase and the expression of human telomerase reverse transcriptase (hTERT), a main determinant of the telomerase enzymatic activity, was progressively downregulated by sodium butyrate. Taken together, it is suggested that sodium butyrate can be a promising chemopreventive agent for leukemic cells and changes in Bcl-2 family expressions, as well as telomerase activity may, play critical roles in sodium butyrate-induced apoptosis in U937 cells.
\end{abstract}

\section{Introduction}

It is now well accepted that apoptosis, a programmed cell death, is a physiological phenomenon that plays an important role in the regulation of tissue development and homeostasis.

Correspondence to: Dr Yung Hyun Choi, Department of Biochemistry, Dongeui University College of Oriental Medicine, Busan 614-052, Korea

E-mail: choiyh@deu.ac.kr

Key words: sodium butyrate, apoptosis, Bcl-2, caspase-3, telomerase, hTERT
Deregulation of apoptosis has been shown to contribute to the pathogenesis of a number of human diseases, including cancer (1). Accumulated data indicate that many anticancer drugs can cause the death of tumor cells through the induction of apoptosis, which is regarded as the preferred way to manage cancer. There are apparently many factors, including Bcl-2 family and caspase proteases, involved in the apoptotic process through the expression of genes, and the characterization of the function of these gene products will help to define the process of cell death at the molecular level $(2,3)$.

In addition to the deregulation of apoptosis, it is increasingly clear that the process of neoplasia is characterized by the activation of telomerase that adds telomeric repeats to the ends of replicating chromosomes, telomeres $(4,5)$. Telomeres are essential units that stabilize the ends of the eukaryotic chromosome and prevent the loss of genetic information. In normal human somatic cells, which show little or no telomerase activity to synthesize new telomeres, the telomeric DNAs progressively shorten with each cell division $(5,6)$. Critically short telomeres are suggested to cause irreversible cell growth arrest and cellular senescence (4-7). Conversely, most tumor cells have mechanisms that compensate for telomere shortening, most commonly through the activation of telomerase, allowing them to stably maintain their telomeres and grow indefinitely. These observations suggest that telomerase reactivation is a rate-limiting step in cellular immortality and carcinogenesis, and telomerase repression can act as a tumor-suppressive mechanism.

Sodium butyrate is a short chain fatty acid normally produced as a result of bacterial fermentation of fiber in mammalian intestines, representing one of the end products of carbohydrate breakdown (8). Previous reports revealed that sodium butyrate is the most effective of the numerous fatty acids produced in the colon for arresting cell proliferation (9). Although the molecular mechanisms by which sodium butyrate exerts these effects are not well understood, sodium butyrate is known as an inhibitor of histone deacetylase (HDAC) (10), which leads to chromatin remodeling and transcriptional modulation of gene expression implicated in diverse cellular processes such as cell cycle progression (11-13), cell differentiation and/or apoptosis (1419). Several studies have highlighted that sodium butyratetreated cancer cells down-regulate the anti-apoptotic molecules $(14,15)$ or up-regulate pro-apoptotic molecules $(16,17)$. In this way, sodium butyrate plays a key role in favouring the intrinsic pathway of apoptosis. Moreover, it 
has been reported that sodium butyrate may also influence the extrinsic pathway of apoptosis, although the molecular mechanisms are still unclear $(18,19)$.

This study was performed to elucidate further the mechanisms of the apoptotic pathway by sodium butyrate and its effect on telomerase activity in human leukemic cell line U937. We report here that, in our study, the exposure of U937 cells to sodium butyrate resulted in a dose-dependent growth inhibition and apoptosis. This increase in apoptosis by sodium butyrate was associated with an increase in Bax expression and an activation of caspase-3. Furthermore, down-regulation of human telomerase reverse transcriptase (hTERT) expression by sodium butyrate treatment was associated with a diminished telomerase activity.

\section{Materials and methods}

Cell culture, sodium butyrate and cell growth inhibition study. The human leukemia cell line U937 was purchased from the American Type Culture Collection (Rockville, MD), and maintained at $37^{\circ} \mathrm{C}$ in a humidified condition of $95 \%$ air and $5 \% \mathrm{CO}_{2}$ in DMEM (Gibco BRL, Gaithersburg, MD) supplemented with $10 \%$ heat-inactivated fetal bovine serum (FBS), $2 \mathrm{mM}$ glutamine, $100 \mathrm{U} / \mathrm{ml}$ penicillin, and $100 \mu \mathrm{g} / \mathrm{ml}$ streptomycin. Sodium butyrate was purchased from Sigma Chemical Co. (St. Louis, MO) and dissolved in dimethyl sulfoxide. For growth inhibition analysis, cells were seeded and exposed to various concentrations of sodium butyrate for $48 \mathrm{~h}$. The cells were trypsinized, washed with phosphatebuffered saline (PBS) and the viable cells were scored with a hemocytometer through exclusion of trypan blue.

Nuclear staining with DAPI. After treatment with sodium butyrate, the cells were washed with PBS and fixed with $3.7 \%$ paraformaldehyde (Sigma) in PBS for $10 \mathrm{~min}$ at room temperature. Fixed cells were washed with PBS, and stained with 4,6-diamidino-2-phenylindole (DAPI, Sigma) solution for $10 \mathrm{~min}$ at room temperature. The cells were washed two more times with PBS and analyzed via a fluorescence microscope.

DNA fragmentation assay. Cells were lysed in a buffer containing $10 \mathrm{mM}$ Tris- $\mathrm{HCl}(\mathrm{pH} 7.4), 150 \mathrm{mM} \mathrm{NaCl}, 5 \mathrm{mM}$ EDTA and $0.5 \%$ Triton X-100 for 30 min on ice. Lysates were vortexed and cleared by centrifugation at 10,000 g for $20 \mathrm{~min}$. Fragmented DNA in the supernatant was extracted with an equal volume of neutral phenol : chloroform : isoamylalcohol $(25: 24: 1, \mathrm{v} / \mathrm{v} / \mathrm{v})$ and analyzed electrophoretically on $1 \%$ agarose gel containing $0.1 \mu \mathrm{g} / \mathrm{ml}$ ethidium bromide $(\mathrm{EtBr}$, Sigma).

Flow cytometric analysis. After treatment with sodium butyrate, the cells were collected by trypsinization, washed with cold PBS, and resuspended in PBS. DNA contents of cells were measured using a DNA staining kit $\left(\right.$ CycleTest $^{\mathrm{TM}}$ Plus Kit, Becton Dickinson, Heidelberg, Germany). Propidium iodide (PI)-stained nuclear fractions were obtained by following the kit protocol. Fluorescence intensity was determined using a FACScan flow cytometer and analyzed by CellQuest software (Becton Dickinson).
RNA extraction and reverse transcription-PCR. Total RNA was prepared using an RNeasy kit (Qiagen, La Jolla, CA) and primed with random hexamers to synthesize complementary DNA using AMV reverse transcriptase (Amersham Corp., Arlington Heights, IL) according to the manufacturer's instructions. Polymerase chain reaction (PCR) was carried out in a Mastercycler (Eppendorf, Hamburg, Germany) with indicated primers in Table I. Conditions for PCR reactions were $1 \mathrm{x}\left(94^{\circ} \mathrm{C}\right.$ for $\left.3 \mathrm{~min}\right) ; 35 \mathrm{x}\left(94^{\circ} \mathrm{C}\right.$ for $45 \mathrm{sec} ; 58^{\circ} \mathrm{C}$ for $45 \mathrm{sec}$; and $72^{\circ} \mathrm{C}$ for $\left.1 \mathrm{~min}\right)$ and $1 \mathrm{x}\left(72^{\circ} \mathrm{C}\right.$ for $\left.10 \mathrm{~min}\right)$. Amplification products obtained by PCR were electrophoretically separated on $1 \%$ agarose gel and visualized by EtBr staining.

Gel electrophoresis and Western blotting. The cells were harvested, lysed, and protein concentrations were quantified using the Bio-Rad protein assay (Bio-Rad Lab., Hercules, $\mathrm{CA}$ ), following the procedure described by the manufacturer. For the Western blot analysis, an equal amount of protein was subjected to electrophoresis on SDS-polyacrylamide gels and transferred to nitrocellulose membranes (Schleicher \& Schuell, Keene, NH) by electroblotting. Blots were probed with the desired antibodies for $1 \mathrm{~h}$, incubated with diluted enzyme-linked secondary antibodies and then visualized by the enhanced chemiluminescence (ECL) according to the recommended procedure (Amersham Corp.). The primary antibodies were purchased from Santa Cruz Biotechnology Inc. (Santa Cruz, CA) and Calbiochem (Cambridge, MA, USA). Peroxidase-labeled secondary antibodies were purchased from Amersham Corp.

Assay of caspase-3, -8 and -9 activity. The enzymatic activity of caspases induced by sodium butyrate was recorded using colorimetric assay kits based on the manufacturer's protocol (R\&D Systems, Minneapolis, MN). Briefly, cells were lysed in a lysis buffer for $30 \mathrm{~min}$ on an ice bath. The lysed cells were centrifuged at $14,000 \mathrm{rpm}$ for $10 \mathrm{~min}$, and $100 \mu \mathrm{g}$ protein was incubated with $50 \mu \mathrm{l}$ of reaction buffer and $5 \mu \mathrm{l}$ of calorimetric tetrapeptides, Asp-Glu-Val-Asp (DEVD)-pnitroaniline (pNA) for caspase-3, Ile-Glu-Thr-Asp (IETD)pNA for caspase-8 and Leu-Glu-His-Asp (LEHD)-pNA for caspase- 9 , respectively, at $37^{\circ} \mathrm{C}$ for $2 \mathrm{~h}$. The optical density of the reaction mixture was quantitated spectrophotometrically at a wavelength of $405 \mathrm{~nm}$.

Telomerase activity assay. Telomerase activity was measured using a PCR-based telomeric repeat amplification protocol (TRAP) enzyme-linked immunosorbent assay (ELISA) kit (Boehringer Mannheim, Mannheim, Germany) according to the manufacturer's description. In brief, cells were treated with sodium butyrate, harvested and $\sim 1 \times 10^{6}$ cells were lysed in $200 \mu \mathrm{l}$ lysis reagent and incubated on ice for $30 \mathrm{~min}$. For the TRAP reaction, $2 \mu \mathrm{l}$ of cell extract (containing $2 \mu \mathrm{g}$ protein) was added to $25 \mu \mathrm{l}$ of reaction mixture with the appropriate amount of sterile water to make a final volume of $50 \mathrm{ml}$. PCR was performed in a Mastercycler as follows: primer elongation $\left(30 \mathrm{~min}, 25^{\circ} \mathrm{C}\right)$, telomerase inactivation $\left(5 \mathrm{~min}, 94^{\circ} \mathrm{C}\right)$ and product amplification by the repeat of 30 cycles $\left(94^{\circ} \mathrm{C}\right.$ for $30 \mathrm{sec}, 50^{\circ} \mathrm{C}$ for $30 \mathrm{sec}, 72^{\circ} \mathrm{C}$ for $\left.90 \mathrm{sec}\right)$. Hybridization and the ELISA reaction were carried out following the manufacturer's instructions. 
Table I. Oligonucleotides used in RT-PCR.

\begin{tabular}{|c|c|c|}
\hline Name & & Sequence of primers \\
\hline \multirow[t]{2}{*}{ Bax } & Sense & 5'-ATG-GAC-GGG-TCC-GGG-GAG-3' \\
\hline & Antisense & 5'-TGG-AAG-AAG-ATG-GGC-TGA-3' \\
\hline \multirow[t]{2}{*}{$\mathrm{Bcl}-2$} & Sense & 5'-CAG-CTG-CAC-CTG-ACG-3' \\
\hline & Antisense & 5'-GCT-GGG-TAG-GTG-CAT-3' \\
\hline \multirow[t]{2}{*}{$\mathrm{Bcl}-\mathrm{X}_{\mathrm{L}}$} & Sense & 5'-CAG CTG CAC CTG ACG-3' \\
\hline & Antisense & 5'-GCT GGG TAG GTG CAT-3' \\
\hline \multirow[t]{2}{*}{ XIAP } & Sense & 5'-GAA-GAC-CCT-TGG-GAA-CAA-CA-3' \\
\hline & Antisense & 5'-CGC-CTT-AGC-TGC-TCT-CTT-CAG-T-3' \\
\hline \multirow[t]{2}{*}{ cIAP-1 } & Sense & 5'-TGA-GCA-TGC-AGA-CAC-ATG-C-3' \\
\hline & Antisense & 5'-TGA-CGG-ATG-AAC-TCC-TGT-CC-3' \\
\hline \multirow[t]{2}{*}{ cIAP-2 } & Sense & 5'-CAG-AAT-TGG-CAA-GAG-CTG-G-3' \\
\hline & Antisense & 5'-CAC-TTG-CAA-GCT-GCT-CAG-G-3' \\
\hline \multirow[t]{2}{*}{ Fas } & Sense & 5'-TCT-AAC-TTG-GGG-TGG-CTT-TGT-CTT-C-3' \\
\hline & Antisense & 5'-GTG-TCA-TAC-GCT-TTC-TTT-CCA-T-3' \\
\hline \multirow[t]{2}{*}{ FasL } & Sense & 5'-GGA-TTG-GGC-CTG-GGG-ATG-TTT-CA-3' \\
\hline & Antisense & 5'-AGC-CCA-GTT-TCA-TTG-ATC-ACA-AGG-3' \\
\hline \multirow[t]{2}{*}{ hTERT } & Sense & 5'-AGC-CAG-TCT-CAC-CTT-CAA-CC-3' \\
\hline & Antisense & 5'-GTT-CTT-CCA-AAC-TTG-CTG-ATG-3' \\
\hline \multirow[t]{2}{*}{ TEP-1 } & Sense & 5'-TCA-AGC-CAA-ACC-TGA-ATC-TGA-G-3' \\
\hline & Antisense & 5'-CCC-CGA-GTG-AAT-CTT-TCT-ACG-C-3' \\
\hline \multirow[t]{2}{*}{ hTR } & Sense & 5'-TCT-AAC-CCT-AAC-TGA-GAA-GGG-CGT-AG-3' \\
\hline & Antisense & 5'-GTT-TGC-TCT-AGA-ATG-AAC-GGT-GGA-AG-3' \\
\hline \multirow[t]{2}{*}{ Sp-1 } & Sense & 5'-ACA-GGT-GAG-VTT-GAC-CTC-AC-3' \\
\hline & Antisense & 5'-GTT-GGT-TTG-CAC-CTG-GTA-TG-3' \\
\hline \multirow[t]{2}{*}{ c-myc } & Sense & 5'-AAG-ACT-CCA-GCG-CCT-TCT-CTC-3' \\
\hline & Antisense & 5'-GTT-TTC-CAA-CTC-CGG-GAT-CTG-3' \\
\hline \multirow[t]{2}{*}{ GAPDH } & Sense & 5'-CGG-AGT-CAA-CGG-ATT-TGG-TCG-TAT-3' \\
\hline & Antisense & 5'-AGC-CTT-CTC-CAT-GGT-GGT-GAA-GAC-3' \\
\hline
\end{tabular}

\section{Results}

Inhibition of the cell viability by sodium butyrate. To test the effect of sodium butyrate on the growth of U937 cells, the cells were treated with different concentrations of sodium butyrate. After 48-h incubation, the viable cells were measured by hemocytometer counts of trypan blue-excluding cells. Exposure of sodium butyrate to U937 cells resulted in a decrease in viable cells in a concentration-dependent fashion (Fig. 1A), as compared to untreated control cells.

Induction of apoptosis by sodium butyrate. To elucidate whether sodium butyrate inhibits the viability of U937 cells by inducing apoptosis, cells treated with sodium butyrate were examined after DAPI staining. As shown in Fig. 1B, nuclei with chromatin condensation and formation of apoptotic bodies, a characteristic of apoptosis, were seen in cells cultured with sodium butyrate in a dose-dependent manner, but very few in control cells. Another hallmark of apoptosis is a degradation of chromosomal DNA at internucleosomal linkages, thus, we analyzed whether DNA fragmentation was induced by sodium butyrate in U937 cells. Following agarose gel electrophoresis of U937 cells treated with sodium butyrate for $48 \mathrm{~h}$, a typical ladder pattern of internucleosomal fragmentation was observed in a dose-dependent manner (Fig. 2A). To quantify the degree of apoptosis, we analyzed the amount of sub-diploid DNA, which contained less DNA than G1 cells, by flow cytometry. As shown by data in Fig. 2B, while the induction of apoptosis was almost negligible (4.16 and $6.85 \%$ compared to $4.10 \%$ of control) at the low concentrations $(0.4$ and $0.8 \mathrm{mM})$, the high concentrations resulted in an increase in apoptosis (16.97 and $31.62 \%$ at 1.6 and $2.0 \mathrm{mM}$, respectively).

Modulation of Bcl-2 family expression and activation of caspase-3 by sodium butyrate. To investigate the apoptotic cascades involved by sodium butyrate, cells were exposed to sodium butyrate and the levels of $\mathrm{Bax}, \mathrm{Bcl}-2$ and $\mathrm{Bcl}-\mathrm{X}_{\mathrm{L}}$ were measured. RT-PCR and immunoblotting data indicated that 
A)

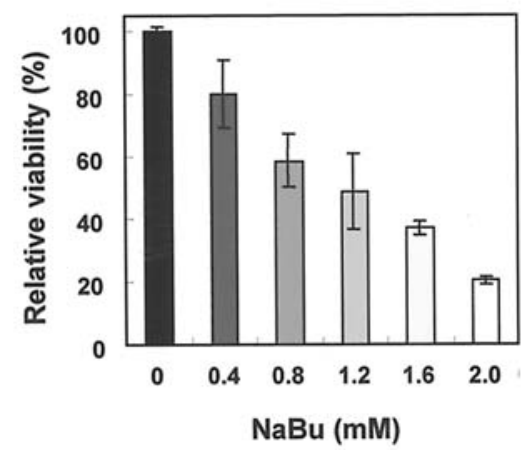

B)
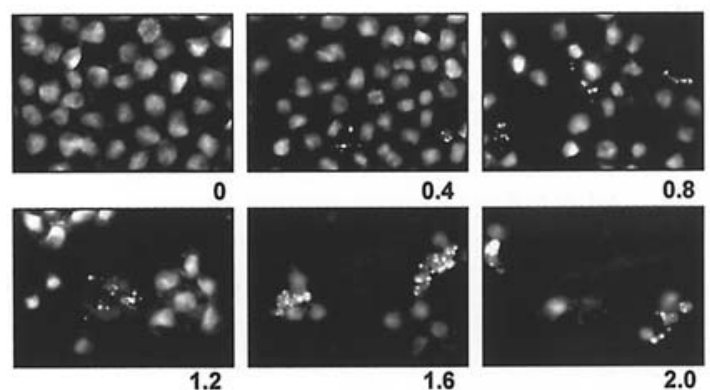

$\mathrm{NaBu}(\mathrm{mM})$

Figure 1. Induction of growth inhibition and apoptotic body of human leukemic U937 cells after treatment with sodium butyrate (NaBu). (A) Cells were plated at $1 \times 10^{3}$ cells per $60-\mathrm{mm}$ plate, and incubated for $24 \mathrm{~h}$. Cells were treated with variable concentrations of sodium butyrate for $48 \mathrm{~h}$. The cells were trypsinized, washed with PBS and the viable cells were scored by hemocytometer counts of trypan blue-excluding cells. Each point represents the means \pm SE of three independent experiments. (B) Cells were incubated with sodium butyrate for $48 \mathrm{~h}$ and then stained with DAPI. After 10-min incubation at room temperature, the cells were washed with PBS and photographed with a fluorescence microscope using blue filter. Magnification, $\mathrm{x} 400$.

A)

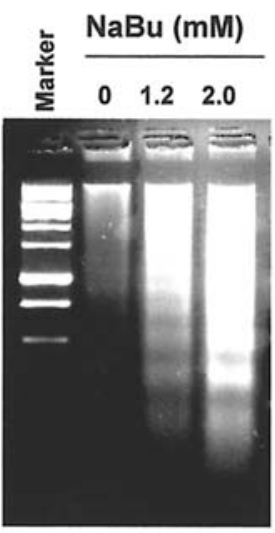

B)

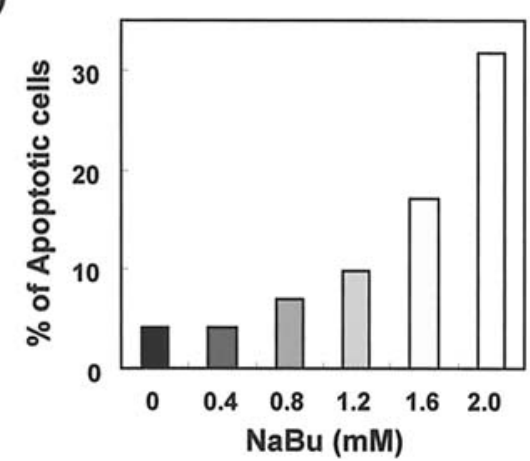

Figure 2. Induction apoptosis of human leukemic U937 cells after treatment with sodium butyrate. (A) Cells were plated at $1 \times 10^{3}$ cells per $60-\mathrm{mm}$ plate, and incubated for $24 \mathrm{~h}$. Cells were treated with variable concentrations of sodium butyrate for $48 \mathrm{~h}$. To analyze fragmentation of genomic DNA, cells were treated for $48 \mathrm{~h}$ with the indicated concentrations of sodium butyrate. Fragmented DNA was extracted and analyzed on $1 \%$ agarose gel. (B) Cells treated for $48 \mathrm{~h}$ with increasing concentration of sodium butyrate showed a dose-dependent increase in the number of apoptotic cells as measured by flow cytometry. The profile represents the increase of sub-G1 population and each point represents the mean of two independent experiments.

the transcriptional and translational levels of Bax expression, a pro-apoptotic gene, were markedly induced in sodium butyrate treated cells, whereas the levels of $\mathrm{Bcl}-2$ and $\mathrm{Bcl}-\mathrm{X}_{\mathrm{L}}$,
A)

$\mathrm{NaBu}(\mathrm{mM})$

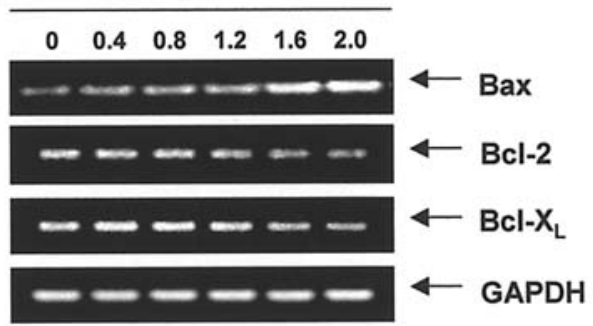

B)

$\mathrm{NaBu}(\mathrm{mM})$

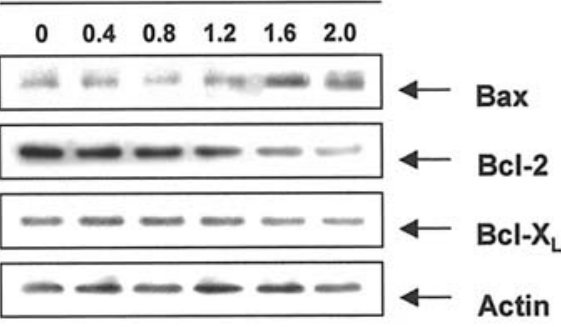

Figure 3. Induction of Bax, and inhibition of $\mathrm{Bcl}-2$ and $\mathrm{Bcl}-\mathrm{X}_{\mathrm{L}}$ by sodium butyrate in U937 human leukemic cells. (A) After 48-h incubation with sodium butyrate, total RNAs were isolated and reverse-transcribed. The resulting cDNAs were subjected to $\mathrm{PCR}$ with $\mathrm{Bax}, \mathrm{Bcl}-2$ and $\mathrm{Bcl}-\mathrm{X}_{\mathrm{L}}$ primers and the reaction products were subjected to electrophoresis in a $1 \%$ agarose gel and visualized by EtBr staining. GAPDH was used as an internal control. (B) The cells were lysed and then cellular proteins were separated by $12 \%$ SDS-polyacrylamide gels and transferred onto nitrocellulose membranes. The membranes were probed with anti-Bax, anti-Bcl-2 and anti-Bcl- $\mathrm{X}_{\mathrm{L}}$ antibodies. Proteins were visualized using an ECL detection system. Actin was used as an internal control.

anti-apoptotic genes, were inhibited in response to sodium butyrate treatment (Fig. 3). Because caspases have been shown to play important roles in the execution of apoptosis, we next measured the effects of sodium butyrate on the caspase activity. As shown in Fig. 4, sodium butyrate-induced apoptosis of U937 cells were associated with a marked increase of caspase- 3 activity in a concentration-dependent fashion, however, caspase- 8 and -9 were not significantly activated by sodium butyrate treatment. 


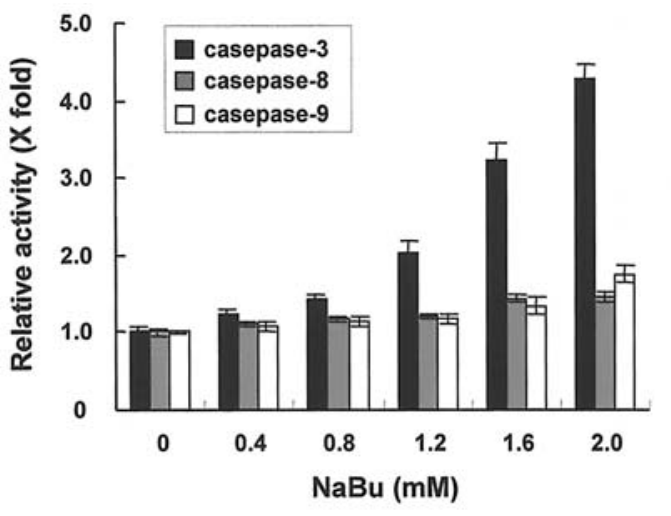

Figure 4. Activation of caspase-3 by sodium butyrate in U937 human leukemic cells. Cell lysates from cells treated with sodium butyrate for $48 \mathrm{~h}$ were assayed for in vitro caspase- $3,-8$ and -9 activity using DEVD-pNA, IETD-pNA and LEHD-pNA-pNA, respectively, as substrates. The released fluorescent products were measured. Data represents the relative means $\pm \mathrm{SE}$ of three independent experiments.

A)

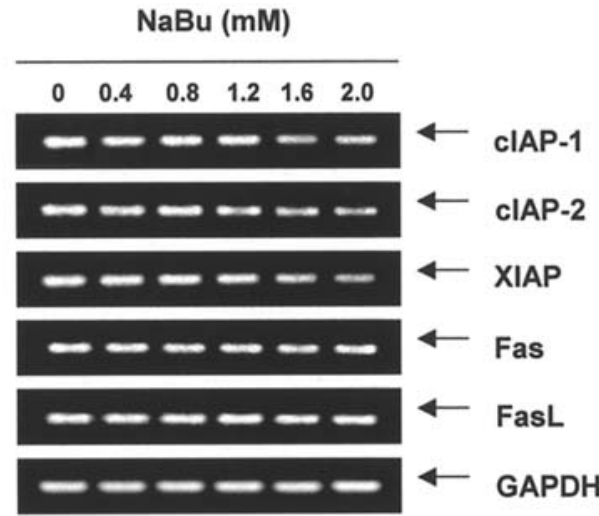

B)

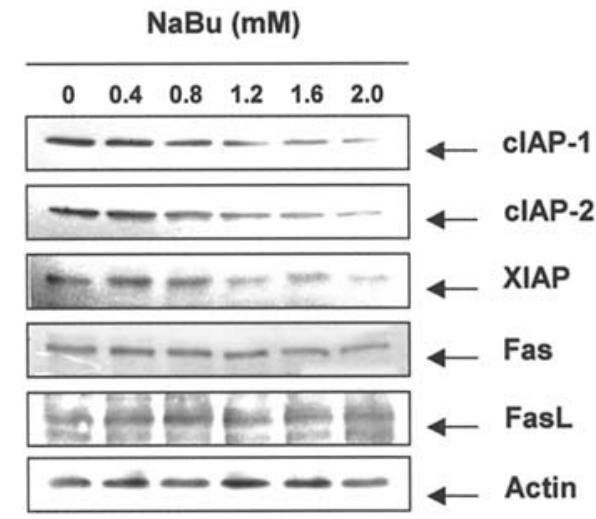

Figure 5. Effect of sodium butyrate in the levels of IAP family and Fas/FasL system members in U937 human leukemic cells. (A) After 48-h incubation with sodium butyrate, total RNAs were isolated and reverse-transcribed. The resulting cDNAs were subjected to PCR with indicated primers and the reaction products were subjected to electrophoresis in a $1 \%$ agarose gel and visualized by EtBr staining. GAPDH was used as an internal control. (B) The cells were lysed and then cellular proteins were separated by $10 \%$ SDSpolyacrylamide gels and transferred onto nitrocellulose membranes. The membranes were probed with the indicated antibodies. Proteins were visualized using an ECL detection system. Actin was used as an internal control.

Effects of sodium butyrate on the levels of IAPs family and Fas/FasL system. Since IAPs family proteins bind to caspases, which lead to caspase inactivation in eukaryotic cells, we further examined the involvement of the IAPs family in sodium butyrate-induced apoptosis of U937 cells. The results indicated that the levels of IAPs family members, such as cIAP-1, cIAP-2 and XIAP, were concentration-dependently down-regulated in sodium butyrate-treated U937 cells (Fig. 5). Fas/FasL system was also a key signaling transduction pathway of apoptosis in cells and tissues, thus we examined the involvement of the Fas/FasL system in U937 cells treated with sodium butyrate. As shown in Fig. 5, Fas and FasL expressions remained unchanged in sodium butyrate-treated cells.

Inhibition of telomerase activity and down-regulation of hTERT by sodium butyrate. In order to determine whether the apoptotic effects of sodium butyrate is associated with the inhibition of telomerase activity, cells were cultured in the absence or presence of sodium butyrate for $48 \mathrm{~h}$, and telomerase activity was measured by a TRAP-ELISA. As shown in Fig. 6A, significant reduction of telomerase activity by sodium butyrate treatment in U937 cells was observed in a concentration-dependent manner. Of components comprising of telomerase, hTERT, human telomerase RNA (hTR) and telomerase-associated protein-1 (TEP-1) are critical regulators of the enzyme activity of telomerase, we therefore examined changes in these expressions on treatment with sodium butyrate. As indicated in Fig. 6B, hTERT mRNA expression was significantly inhibited by sodium butyrate treatment. In addition, the mRNA levels of two transcription factors, Sp-1 and c-myc, which play crucial roles in the regulation of hTERT transcription, were also down-regulated by sodium butyrate treatment.

\section{Discussion}

Recent studies have been conducted to show that anti-tumor agents may impinge on cellular signaling pathways and often may recruit them to induce apoptosis in cancer cells. Apoptosis is a tightly regulated progress under the control of several signaling pathways. One major group of genes that regulate apoptosis is the Bcl-2 family. It has been reported that Bcl-2 members protect against multiple signals that lead to cell death, whereas Bax members induce apoptosis, indicating that Bcl-2 family regulates a common cell death pathway and functions at a point where various signals converge $(2,3)$. Bcl-2 acts to inhibit cytochrome $c$ translocation from mitochodria to cytoplasm, thereby blocking the caspase activation step of the apoptotic process $(2,20)$. Thus, it has been suggested that the ratio between the level of proapoptotic Bax and that of the anti-apoptotic factor Bcl-2 determines whether a cell responds to an apoptotic signal.

The present results clearly demonstrate that sodium butyrate induces apoptosis in human leukemia U937 cells, which appears to account for its anti-proliferating activity (Figs. 1 and 2). As shown in Fig. 3, there was a concentration-dependent down-regulation of Bcl-2 members such as Bcl-2 and Bcl- $\mathrm{X}_{\mathrm{L}}$ in sodium butyrate-treated U937 cells, but the levels of Bax were up-regulated, resulting in an increase in the ratio of $\mathrm{Bax} / \mathrm{Bcl}-2$ and/or Bcl-X . $_{\text {. }}$

Caspases are synthesized initially as single polypeptide chains representing latent precursors that undergo proteolytic 
A)

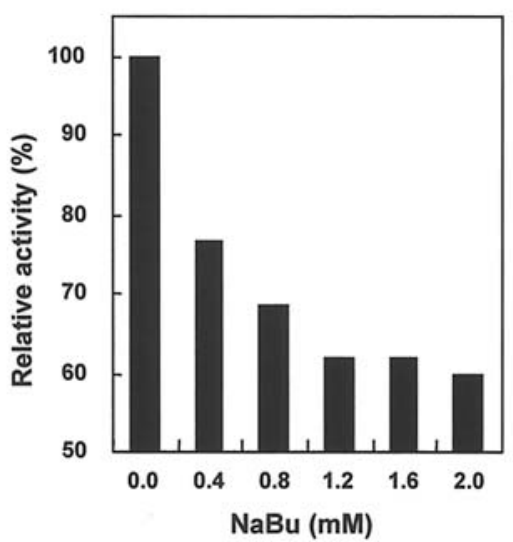

B)

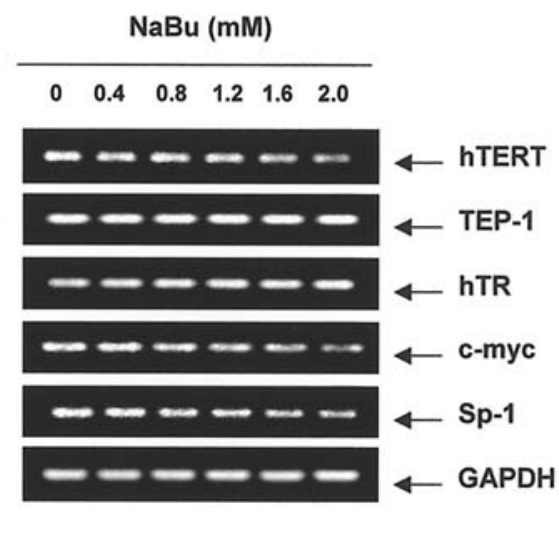

Figure 6. Inhibition of telomerase activity by sodium butyrate treatment in U937 human leukemic cells. (A) After 48-h incubation with sodium butyrate, telomerase activity of U937 cells was measured using a TRAP-ELISA kit as described in Materials and methods. For one sample, 2x105 cells were lysed, and 1/100 was used in the assay. Results are expressed as the relative means of two separate experiments. (B) After 48-h incubation with sodium butyrate, total RNAs were isolated and RT-PCR was performed using indicated primers. The amplified PCR products were run in a $1 \%$ agarose gel and visualized by EtBr staining. GAPDH was used as a house-keeping control gene.

processing at specific residues to produce subunits that form the active heterotetrameric protease $(3,21)$. In addition, the IAP family has been reported to exert antiapoptotic effects due to their function as direct inhibitors of activated caspases, regulating cell cycle progression and modulating receptor-mediated signal transduction. Therefore, downregulation of IAPs relieves the triggering block of proapoptotic signaling and the execution caspases-3, -7 and -9 , thus activating cell death $(22,23)$. The Fas/FasL system is also a key signal transduction pathway of apoptosis. Binding Fas ligand to Fas receptor leads to receptor oligomerization and formation of death-inducing signaling complex, followed by activation of caspase- 8 , then further activating a series of caspase cascades resulting in apoptotic cell death $(24,25)$. Further studies have shown that exposure of U937 cells to sodium butyrate caused a proteolytic activation of caspase-3, but not caspase-8 and -9 (Fig. 4), and a down-regulation of IAP family expression (Fig. 5). However, sodium butyrate treatment did not affect the Fas and FasL levels in U937 cells (Fig. 5). Therefore, the present data indicate that the apoptotic effects of sodium butyrate on U937 cells are associated with activation of caspase-3, a main executioner of apoptosis, through an increase of Bax expression and the alteration of IAP expression.

Telomere length is primarily controlled by three major components; hTERT, hTR and TEP-1 in human cells. There is a good correlation between expression of hTERT mRNA and the presence of telomerase activity in extracts from tissue culture cells and normal and cancer tissues $(5,18)$. Additionally it has been reported that the overexpression of $\mathrm{Bcl}-2$ in human cancer cells resulted in an increased telomerase activity and a resistance to apoptosis, indicating a link between Bcl-2 expression and the telomerase activity in human cancer cells (26). Additionally, it has been observed that overexpression of Bcl-2 and the caspase inhibitor could protect cells against apoptosis by telomerase inhibitors (27), suggesting that telomerase is a site of action before caspase is activated and mitochondrial becomes dysfunctional. These observations suggest that the modification of hTERT expression or telomerase activity may be a potential therapeutic modality for the treatment of human cancers. As demonstrated in Fig. 6A, sodium butyrate treatment resulted in the marked inhibition of the telomerase activity and hTERT mRNA expression of U937 cells. On the other hand, the 200- to 400-bp region proximal to the transcription initiation site of hTERT promoter is responsible for most of its transcriptional activity. Previous studies have provided evidence that Sp-1 and c-myc bind to the core promoter of hTERT and regulate hTERT transcriptional regulation $(28,29)$. However, in some cancer cells, telomerase activity can apparently be regulated independently on Sp-1 and/or c-myc $(30,31)$. In the present study, the levels of both Sp-1 and c-myc mRNA expressions in U937 cells were concentration-dependently inhibited by sodium butyrate (Fig. 6B). Thus the results demonstrated that an increased apoptosis of U937 cells caused by sodium butyrate was accompanied by a significant inactivation of telomerase activity through an inhibition of hTERT mRNA expression which was associated with down-regulation of Sp-1 and c-myc (Fig. 6). Although both activation of telomerase activity and Bcl-2 deregulation have been widely detected in human cancer cells, and telomerase might be an important factor in suppressing apoptotic signaling cascades $(4,22)$, it remains unclear whether there was any linkage between the deregulation of Bcl-2 and telomerase activity by sodium butyrate.

In conclusion, our results indicated that sodium butyrate potently suppresses the proliferation of U937 human leukemic cells by inducting apoptosis through an increase of Bax expression and activation of caspase-3. The growth inhibitory effects of sodium butyrate were also associated with a specific inhibition of hTERT expression and telomerase activity. Although further studies are needed, the present work suggests that loss of telomerase activity may be a good surrogate biomarker for assessing anti-tumor activity of sodium butyrate. 


\section{Acknowledgements}

This work was supported by the Korea Research Foundation Grant funded by the Korean Government (R05-2004-00010672-0).

\section{References}

1. Schultz DR and Harrington WJ Jr: Apoptosis: programmed cell death at a molecular level. Semin Arthritis Rheum 32: 345-369, 2003.

2. Adams JM and Cory S: Life-or-death decisions by the Bcl-2 protein family. Trends Biochem Sci 26: 61-66, 2001.

3. Earnshaw WC, Martins LM and Kaufmann SH: Mammalian caspases: structure, activation, substrates, and functions during apoptosis. Annu Rev Biochem 6: 383-424, 1999.

4. Hahn WC and Meyerson M: Telomerase activation, cellular immortalization and cancer. Ann Med 33: 123-129, 2001

5. Oulton R and Harrington L: Telomeres, telomerase, and cancer: life on the edge of genomic stability. Curr Opin Oncol 12: 74-81, 2000.

6. Odago FO and Gerson SL: Telomerase inhibition and telomere erosion: a two-pronged strategy in cancer therapy. Trends Pharmacol Sci 24: 328-331, 2003.

7. Autexier $\mathrm{C}$ and Greider CW: Telomerase and cancer: revisiting the telomere hypothesis. Trends Biochem Sci 21: 387-391, 1996.

8. Cummings JH: Short chain fatty acids in the human colon. Gut 22: 763-779, 1981 .

9. Kruh J: Effects of sodium butyrate, a new pharmacological agent, on cells in culture. Mol Cell Biochem 42: 65-82, 1982.

10. Candido EP, Reeves R and Davie JR: Sodium butyrate inhibits histone deacetylation in cultured cells. Cell 14: 105-113, 1978.

11. Archer SY, Johnson J, Kim HJ, Ma Q, Mou H, Daesety V, Meng S and Hodin RA: The histone deacetylase inhibitor butyrate downregulates cyclin B1 gene expression via a p21/ WAF-1-dependent mechanism in human colon cancer cells. Am J Physiol Gastrointest Liver Physiol 289: G696-G703, 2005.

12. Chopin V, Toillon RA, Jouy N and Le Bourhis X: P21(WAF1/ CIP1) is dispensable for G1 arrest, but indispensable for apoptosis induced by sodium butyrate in MCF-7 breast cancer cells. Oncogene 23: 21-29, 2004.

13. Wang YF, Chen NS, Chung YP, Chang LH, Chiou YH and Chen CY: Sodium butyrate induces apoptosis and cell cycle arrest in primary effusion lymphoma cells independently of oxidative stress and p21(CIP1/WAF1) induction. Mol Cell Biochem 14: 1-9, 2006.

14. Madigan MC, Chaudhri G, Penfold PL and Conway RM: Sodium butyrate modulates p53 and Bcl-2 expression in human retinoblastoma cell lines. Oncol Res 11: 331-337, 1999.
15. Li X, Marani M, Mannucci R, Kinsey B, Andriani F, Nicoletti I, Denner L and Marcelli M: Overexpression of BCL-X (L) underlies the molecular basis for resistance to staurosporineinduced apoptosis in PC-3 cells. Cancer Res 61: 1699-1706, 2001.

16. Tsai LC, Hung MW, Chang GG and Chang TC: Apoptosis induced by the sodium butyrate in human gastric cancer TMK-1 cells. Anticancer Res 20: 2441-2448, 2000.

17. Litvak DA, Hwang KO, Evers BM and Townsend CM: Induction of apoptosis in human gastric cancer by sodium butyrate. Anticancer Res 20: 779-784, 2000.

18. Hara I, Miyake H, Hara S, Arakawa S and Kamidono S: Sodium butyrate induces apoptosis in human renal cell carcinoma cells and synergistically enhances their sensitivity to anti-Fas-mediated cytotoxicity. Int J Oncol 17: 1213-1218, 2000.

19. Hernandez A, Thomas R, Smith F, Sandberg J, Kim S, Chung DH and Evers BM: Butyrate sensitizes human colon cancer cells to TRAIL-mediated apoptosis. Surgery 130: 265-272, 2001.

20. Decaudin D, Marzo I, Brenner C and Kroemer G: Mitochondria in chemotherapy-induced apoptosis: a prospective novel target of cancer therapy. Int J Oncol 12: 141-152, 1998.

21. Stennicke HR and Salvesen GS: Properties of the caspases. Biochim Biophys Acta 1387: 17-31, 1998.

22. Hengartner MO: The biochemistry of apoptosis. Nature 407: 770-776, 2000.

23. Roy N, Deveraux QL, Takahashi R, Salvesen GS and Reed JC: The c-IAP-1 and c-IAP-2 proteins are direct inhibitors of specific caspases. EMBO J 16: 6914-6925, 1997.

24. Nagata S and Golstein P: The Fas death factor. Science 267: 1449-1456, 1996

25. Jiang C, Yang YF and Cheng SH: Fas ligand gene therapy for vascular intimal hyperplasia. Curr Gene Ther 4: 33-39, 2004.

26. Mandal M and Kumar R: Bcl-2 modulates telomerase activity. J Biol Chem 72: 14183-14187, 1997.

27. Fu W, Begley JG, Killen MW and Mattson MP: Anti-apoptotic role of telomerase in pheochromocytoma cells. J Biol Chem 274: 7264-7271, 1999.

28. Kyo S, Kanaya T, Takakura M, Tanaka M, Yamashita A, Inoue $\mathrm{H}$ and Inoue $\mathrm{M}$ : Expression of human telomerase subunits in ovarian malignant, borderline and benign tumors. Int J Cancer 80: 804-809, 1990.

29. Kyo S, Takakura M, Taira T, Kanaya T, Itoh H, Yutsudo M, Ariga $\mathrm{H}$ and Inoue $\mathrm{M}$ : $\mathrm{Sp} 1$ cooperates with c-Myc to activate transcription of the human telomerase reverse transcriptase gene (hTERT). Nucleic Acids Res 28: 669-677, 2000.

30. Drissi R, Zindy F, Roussel MF and Cleveland JL: C-Mycmediated regulation of telomerase activity is disabled in immortalized cells. J Biol Chem 276: 29994-30001, 2001

31. Xiao X, Sidorov IA, Gee J, Lempicki RA and Dimitrov DS: Retinoic acid-induced downmodulation of telomerase activity in human cancer cells. Exp Mol Pathol 79: 108-117, 2005. 